\title{
Koronavirüs Hastalığı 2019 (Covid-19) Pandemisi ile Karşı Karşıya Kalan Sağlık Çalışanları Arasında Tükenmişlik Sendromu
}

Burn-Out Syndrome Among Healthcare Professionals Facing

The Novel Coronavirus Disease 2019 (Covid-19) Pandemic

\author{
Șeyhmus TUNC $^{1}(\mathbb{D})$, Mehmet Rifat GÖKLÜ ${ }^{1}$
}

${ }^{1}$ Sağlık Bilimleri Üniversitesi, Gazi Yaşargil Eğitim ve Araştırma Hastanesi, Kadın Hastalıkları ve Doğum Departmanı, Diyarbakır, Türkiye

Öz.

Amaç: Bu çalışmada üçüncü basamak pandemi hastanesinin kadın hastalıkları ve doğum ünitesinde görevli doktor hemşire, ebe ve anestezi teknisyenlerinde tükenmişlik sendromu ile ilişkili risk faktörlerinin belirlenmesi amaçlanmıştır.

Materyal ve metod: Sosyo-demografik bilgileri ve iş yeri ile ilgili özellikleri içeren anket formu ile Maslach Tükenmişlik Ölçeğini 1-15 Eylül 2021 tarihleri arasında dolduran 316 katılımcı çalışmaya dahil edilmiștir.

Bulgular: Genç çalışanlarda duyarsızlaşma skoru $(p=0,001)$, kadınlarda duygusal tükenmişlik ve kişisel başarı skorları anlamlı olarak yüksek saptandı ( $p=0,043$ ve $p=0,003$ ). Kadın hastalıkları ve doğum uzmanlarında diğer branşlara göre anlamlı olarak daha yüksek duygusal tükenmişlik ve duyarsızlaşma skorları bulunmuştur ( $p=0,021$ ve $p=0,038)$. Çalışılan birimler incelendiğinde, yoğun bakımda çalışanlarda en yüksek, poliklinikte çalışanlarda en düşük duyarsızlaşma tespit edilmiştir $(p=0,039)$. Toplam hizmet süresindeki artış ile duyarsızlık skorundaki azalış ve kişisel başarı skorundaki yükseliş korele bulunmuştur ( $p=0,003$ ve $p=0,004)$. Meslekten beklentilerinin karşılanmadığını ya da kısmen karşılandığın belirtenlerde duygusal tükenmişlik skoru anlamlı yüksek saptanmıştır $(p=0,032)$. Ekstra saat çalışanlarda duygusal tükenmişlik ve duyarsızlaşma skorları anlamlı yüksek bulunmuştur $(p=0,004$ ve $p=0,012)$. Fiziki koşulların yetersiz olduğunu bildiren çalışanlarda duygusal tükenmişlik skorunda anlamlı yükseklik saptanmıştır $(p<0,001)$. COVID-19'lu hastalara doğrudan hizmet sunan grupta duygusal tükenmişlik ve duyarsızlaşma skorunda anlamlı yükseklik, kişisel başarı skorunda anlamlı düşüklük saptanmıştır( $p=0,014, p=0,003$ ve $p=0,014)$.

Sonuç: COVID-19 pandemisi çalışanlarda tükenmişlik sendromu riskinde artışa neden olmaktadır. Ağır çalışma koşulları ve çalışma ortamındaki fiziki yetersizlikler tükenmişlik sendromu riskini artıran diğer nedenlerdendir.

Anahtar Kelimeler: COVID-19 Pandemisi, Tükenmişlik Sendromu, Kadın hastalıkları ve Doğum

Abstract

Background: This study aimed to determine the risk factors associated with burnout syndrome in doctors, nurses, midwives, and anesthesia technicians working in the gynecology and obstetrics unit of the tertiary pandemic hospital. Materials and Methods: A total of 316 participants who filled out the Maslach Burnout Scale with a questionnaire including socio-demographic information and workplace-related characteristics between 1-15 September 2021 were included in the study.

Results: Depersonalization scores were significantly higher in young employees $(p=0.001)$, and emotional exhaustion and personal accomplishment scores were significantly higher in female employees $(p=0.043$ and $p=0.003$, respectively). Significantly higher emotional exhaustion and depersonalization scores were found in obstetricians compared to the clinicians from the other departments ( $p=0.021$ and $p=0.038$, respectively). When the departments were analyzed, the highest depersonalization score was detected in those working in the intensive care unit, and the lowest in those working in the outpatient department $(p=0.039)$. The increase in the duration of working life and the decrease in the depersonalization score and an increase in the personal accomplishment score were found to be significantly correlated ( $p=0.003$ and $p=0.004$, respectively). The emotional exhaustion score was found to be significantly higher in those who stated that their expectations from the profession were not met or partially met $(p=0.032)$. Emotional exhaustion and depersonalization scores were found to be significantly higher in those who worked additional shifts ( $p=0.004$ and $p=0.012$, respectively). A significantly higher emotional exhaustion score was found in the medical staff who reported inadequacies in the physical work environment $(p=<0.001)$. Significantly higher levels of emotional exhaustion and depersonalization scores, and a significantly lower personal accomplishment score were found in healthcare workers who provided medical care to COVID-19 patients $(p=0.014, p=0.003$, and $\mathrm{p}=0.014$, respectively)

Conclusions: The COVID-19 pandemic causes an increased risk of burnout syndrome in employees. Heavy working conditions and inadequacies in the physical work environment are other reasons that increase the risk of burnout syndrome.

Keywords: COVID-19 pandemic, Burn-out Syndrome, Gynecology and Obstetrics

\section{Sorumlu Yazar / Corresponding Author}

\section{Dr. Şeyhmus TUNÇ}

Sağlık Bilimleri Üniversitesi, Gazi Yaşargil Eğitim ve Araştırma Hastanesi, Kadın Has talıkları ve Doğum Departmanı, Diyarbakır, Türkiye.

E-mail: drseyhmustunc@hotmail.com

Geliş tarihi / Received: 19.10.2021

Kabul tarihi / Accepted: 04.11.2021

DOI: $10.35440 /$ hutfd.1012004 


\section{Giriş}

Tükenmişlik "gücünü yitirmiş olma, çaba gösterememe durumu" olarak tanımlanmaktadır. Tükenmişlik kavramı İlk defa 1974 yılında Herbert J Freudenberger'in yazısıyla literatüre girmiştir. Freudenberger tükenmişliği "güç, enerji ya da kaynaklara aşırı talep duyulması nedeniyle oluşan başarısızlık, yıpranma ve bitkinlik durumu" olarak tarif etmiştir (1). Tükenmişlik sendromu fiziksel ve davranışsal bulgularıyla bir meslek hastalığı olarak kabul edilmiştir (2). Maslach, tükenmişliği, işyerinde stres oluşturan unsurlara tepki olarak uzun dönemde ortaya çıkan psikolojik bir sendrom olarak tanımlamış ve günümüzde kabul gören bu tanımı üç ana başlıkta gruplandırmıştır. Bu başlıklar duygusal tükenme, duyarsızlaşma ve kişisel başarı olarak adlandırılmıştır(3). Duygusal tükenme tükenmişliğin ilk ve en önemli bulgusudur (4). Bireyde bitkinlik, mental ve emosyonel yönden yıpranmışlık belirtileri vardır (3). Taleplere cevap verememe durumu söz konusudur (4). Bu durum insan ile birebir ilişkide olunan mesleklerde daha fazla görülmektedir (5).

Duyarsızlaşma hizmet verilen gruba karşı aldırmazlık, duygudan yoksun davranış ve tutumda bulunma durumudur (3). Çalışanlar hem hizmet ettikleri insanlara hem de çalıştıkları kuruma kayıtsızdır. Umursamaz tavırlar sergileyebilirler ve bu durumdan rahatsızlık duymazlar (6). Kişisel başarısızlık hissi, bireyin kendisini olumsuz değerlendirme eğiliminde olması olarak tanımlanabilir (3). Birey yaşadığı tükenmişlik nedeniyle bozulan davranışları ile toplumun ya da çalıştığı kurumun beklentileri arasında tutarsızlık olduğunu fark eder ve yetersizlik hissine kapılabilir (4). Olumsuz fikirler, başarısızlık ve suçluluk duygusu depresyona neden olabilir (7).

Maslach'a göre duygusal tükenmişlik duyasızlaşmayı, duyarsızlaşma da kişisel başarıda düşüş hissini doğurur (3). Buna göre, tükenmişlik stres kaynağına verilen ilk tepki olan duygusal tükenmeyle başlar. Birey, savunma mekanizması olarak duyarsızlaşmaya ve insan ilişkilerinde daha mesafeli olmaya başlar . Durum ilerledikçe beklentilere cevap veremediğini, yetersiz ve başarısız olduğunu düşünür (3).

Son 10 yılda tükenmişlik sendromu ile ilgili yapılan çalışmalarda ciddi artış görülmektedir (8). Tükenmişlik sendromu insidansı Avrupa Birliği üyesi ülkelerde \%10 (\%4,3-20,6 Finlandiya-Slovenya) iken, Avrupa Birliğine üye olmayan ülkelerde \%17 (\%13-25 Arnavutluk-Türkiye) raporlanmıştır (11).

Sağıı profesyonellerinin yaşadığı mesleki stres hem çalışanların sağığını bozarak hem de sunulan sağlık hizmetini verimsiz kılarak dünya ekonomisi için ciddi bir problem haline gelmiştir (10). 2017'de ABD'de tükenmişlik sendromu doktor grubunun en az \%50'sinde tespit edilmiş ve sağlık çalışanları arasında endişe verici seviyelere ulaştığı görülmüştür (10). Özellikle cerrahi kliniklerde çalışanlar daha yüksek duygusal tükenmişlik riskine sahiptirler (8). Sağıı çalışanları arasında tükenmişlik sendromu görülme sıklığında her yıl \%4 oranında artış saptanmıştır (11). Sağlık çalışanları arasında çok yüksek oranlarda görülen tükenmişlik sendromunun çaIışanların sağlık durumunu bozduğu, verilen sağlık hizmetinin kalitesini düşürdüğü ve sağlık sistemine ciddi ekonomik yük bindirdiği aşikardır.
Pandemi, sağlık sisteminde imkanların ve insan gücünün verimli kullanılması gerektiğini bizlere bir kere daha göstermiştir. Bu bağlamda pandemi nedeniyle daha da artan iş yükünün sağlık çalışanları üzerindeki olumsuz psikolojik etkilerine dikkat çekerek, çözüm yollarına katkıda bulunmayı hedefliyoruz.

Çalışmamızda üçüncü basamak bir pandemi hastanesi olan Diyarbakır Gazi Yaşargil Eğitim ve Araştırma Hastanesi KadınDoğum ve Çocuk Kliniklerinde görevli doktor, ebe, hemşire ve anestezi teknisyenlerinden oluşan katılımcıların sosyodemografik özellikleri ve çalışma koşulları ile tükenmişlik durumları arasındaki ilişkinin araştırıması amaçlandı.

\section{Materyal ve Metod}

Çalışmamız bir pandemi hastanesi olan Diyarbakır Gazi Yaşargil EAH Kadın Hastalıkları ve Doğum ve Çocuk Hastalıkları ünitelerinde yapılmış bir anket çalışmasıdır. Çalışma için Sağlık Bilimleri Üniversitesi Gazi Yaşargil Eğitim Ve Araştırma Hastanesi Klinik Araştırmalar Etik Kurulundan etik onayı alındı (08/10/2021 tarih ve 893 sayılı yazı). Çalışmanın dizayn ve uygulanışında Helsinki sözleşmesi maddelerine bağlı kalındı.

Çalışmamız 1-30 Eylül 2021 tarihleri arasında gönüllülük esasına dayalı yürütüldü. Doktor, hemşire, ebe ve anestezi teknikerlerinden oluşan 316 katılımcıya anket yöntemiyle ulaşıldı. Katılımcıların sosyo-demografik özellikleri ve çalışma koşulları ile tükenmişlik düzeyleri arasındaki ilişki araştırıldı. Yazılı onamları alınan katılımcılardan, kapalı uçlu sorularla çalışma koşullarını ve sosyo-demografik bilgilerini sorgulayan bir anket ile tükenmişlik ölçeği anketini doldurmaları istendi. Katılımcıların isim bilgileri istenmedi. Tükenmişlik ölçeği olarak C. Ergin tarafından 1992 yılında geçerlilik ve güvenirlilik çalışmaları yapılarak Türkiye koşullarına valide edilmiş Maslach Tükenmişlik Envanteri (MTE) kullanıldı (12).

MTE toplam 22 adet 5'li likert tip (kapalı uçlu psikometrik anket soruları) sorudan oluşmaktadır. Soruların dokuz tanesi $(1,2,3,6,8,13,14,16$ ve 20 . sorular) duygusal tükenmişlik boyutunu, sekiz tanesi $(4,7,9,12,17,18,19$ ve 21 . sorular) kişisel başarı boyutunu ve geriye kalan beş tanesi de duyarsızlaşma boyutunu skorlamaktadır. Anket sonuçlarında yüksek duygusal tükenmişlik ve duyarsızlaşma skoru ile düşük kişisel başarı skoru yüksek düzeyde tükenmişliği işaret etmektedir (1). Duygusal tükenmişlik skoru için 20 ve altındaki skorlar düşük, 21-27 orta, 28 ve üstündeki skorlar yüksek; duyarsızlaşma skoru için 8 ve altındaki skorlar düşük, 9-12 orta, 13 ve üstündeki skorlar yüksek; kişisel başarı skoru için: 23 ve altındaki skorlar düşük, 24-27 arası orta, 28 ve üstü skorlar yüksek olarak değerlendirilmiştir (13). Birebir hasta ile iletişimi olan, sağlık hizmetine doğrudan katkı sunan doktor, ebe, hemşire ve anestezi teknisyenleri dışındaki gruplar çalışmamıza dahil edilmemiştir. Çalışmamız üçüncü basamak ve refere bir merkezde yapılmıştır. Cerrahi branşların ve özellikle de kadın hastalıkları ve doğum branşının yüksek tükenmişlik riski ile birlikteliği göz önüne alınmış ve tüm paydaşlara yüksek katılım oranıyla ulaşılmıştır. 


\section{İstatistiksel Analiz}

Anketler çalışmacılar tarafından manuel olarak skorlandı ve elde edilen verilerin değerlendirilmesinde SPSS 26.0 (IBM SPSS Statistics for Windows, Version 26.0. Armonk, NY: IBM Corp.) paket programı kullanılmıştır. Kolmogrov-Smirnov ve Shapiro-Wilk gibi normallik testlerinin yanında ilgili dağııım grafiklerinin de incelenmesi sonucunda değişkenlerin gruplar bazında, normal dağılım varsayımlarını sağlayıp sağlamadıkları araştırılmış bunun gereği olarak da parametrik ya da parametrik olmayan test yöntemleri seçilmiştir. Bağımsız iki grubun sürekli nicel değişkenlerce kıyaslanmasında Student's t test ya da Mann Whitney U test kullanılırken, ikiden fazla bağımsız grup arasındaki farklar; Tek Yönlü Varyans Analizi ve/veya Kruskal Wallis varyans analizi ile değerlendirilmiş, farklıı̆ın anlamlı bulunması durumunda posthoc çoklu karşılaştırma testleri farklılı̆ı yaratan gruplar tespit edilmiş ve ilgili tablolarda harf indisleri kullanılarak gösterilmiştir. Kategorik değişkenlerin gruplardaki dağıımlarının test edilmesinde Ki-kare ya da Fisher'in exact testi kullanımış, çalışma sonucunda elde edilen sonuçlar Ortalama \pm Standart sapma ve Ortanca - Değişim Genişliği kullanılarak özetlenmiştir. Tanımlayıcı tipte bir araştırma olan çalışmada kategorik değişkenlere ilişkin frekanslar ve yüzdelikler verilmiş, grafikler yardımıyla görsel olarak da özetlenmiştir. Çalışmada istatistiksel anlamlııı sınırı olarak $p<0,05$ alınmıştır.

\section{Bulgular}

Çalışmaya 316 sağlık çalışanı katılmıştır. Katıımcıların yaklaşı \% $70^{\prime} i 29$ yaş ve üzerindedir. Üçte ikisini kadın ve evli çalışanlardan oluşmuştur. Katılımın yaklaşık \%65'ini ebe-hemşire grubu oluşturmuştur. Doktor grubunun ise \%37'sini çocuk, \%31'ini kadın doğum ve \%16'sını anestezi uzmanları oluşturmuştur. Katılımcılar arasında sigara tüketimi $68 \%$ iken alkol tüketimi nadir görülmüştür (Tablo 1).

Katılımcıların yaklaşık \%63'ünün mesleki deneyimi 10 yııın üzerindedir. Mesleği isteyerek seçtiğini belirtenlerin oranı yaklaşık \%67 iken çok küçük kısmı mesleki beklentisinin karşılandığını ve mesleklerinin toplumdan hak ettiği değeri gördüğünü belirtmiştir (sırasıyla \%0,32-3,81). Mesleğini ön planda ekonomik nedenle sürdürenlerin oranı yaklaşı $\% 66$, severek yapanların oranı yaklaşık \%26 bulunmuştur. Her iki katılımcıdan biri çalışırken hastalardan sık ya da çok sık olumsuz davranış gördüğünü ifade etmiştir. Katılımcıların $\% 83^{\prime}$ ü gece ya da ek mesai yaparken $\% 97$ 'si çalışıı̆ı ortamın fiziki koşullarını yetersiz bulmuştur. Katıımcıların \%60'ı COVID-19 hastalara sağlık hizmet sunduğunu bildirmiştir (Tablo 2).

Gençlerde, 29 yaş ve üzeri gruba göre duyarsızlaşma skoru anlamlı yüksek bulundu( $\mathrm{p}=0.001)$. Kişisel başarı skorunda 39 yaş üzeri grup ile 29 yaş altı grup arasındaki fark anlamlı bulunmuştur $(p=0,015)$. Kadın çalışanlarda duygusal tükenmişlik ve kişisel başarı skorları anlamlı yüksek saptanırken $(p=0,043$ ve $p=0,003)$ medeni hal ile skorlar arasında anlamlı ilişki saptanmamıştır. Hastanede çalışma süresi 1-5 yıl ara- sında olanlarda, çalışma süresi >10 yıl olanlardan anlamlı şekilde yüksek duygusal tükenmişlik skoru saptanırken çalışma süresi >10 yıl olanlarda duyarsızlaşma skoru anlamlı düşük saptanmıştır $(p=0, .047$ ve $p=0,025)$. Toplam hizmet süresindeki artış ile duyarsızlık skorunda azalış ve kişisel başarı skorunda yükseliş anlamlı bulunmuştur ( $p=0,003$ ve $p=0,004)$. Meslekten beklentilerinin karşılanmadığını ya da kısmen karşılandığını belirtenlerde duygusal tükenmişlik skoru anlamlı yüksek saptanmıştır $(p=0,032)$. Mesleğini severek yapan grupta duygusal tükenmişlik skoru anlamlı düşük bulunmuştur $(p=<0,001)$. Olumsuz hasta davranışına maruziyet hem duygusal tükenmişlik hem de duyarsızlaşma skorlarında anlamlı yükseklikle beraber saptanmıştır $(p=<0,001)$. Ek/gece mesaisi şeklinde çalışanlarda duygusal tükenmişlik ve duyarsızlaşma skorları anlamlı yüksek bulunmuş ( $p=0,004$ ve $p=0,012$ ), fiziki koşulların yetersiz olduğunu bildiren grupta da duygusal tükenmişlik skorunda anlamlı yükseklik saptanmıştır $(p<0,001)$.

Tablo 1. Sosyodemografik özellikler

\begin{tabular}{|c|c|c|c|}
\hline & & $\mathbf{n}$ & $\%$ \\
\hline \multirow{3}{*}{ Yaş, yıl } & $<29$ & 57 & 18,04 \\
\hline & $29-39$ & 139 & 43,99 \\
\hline & $>39$ & 120 & 37,97 \\
\hline \multirow{2}{*}{ Cinsiyet } & Erkek & 87 & 27,53 \\
\hline & Kadın & 229 & 72,47 \\
\hline \multirow{2}{*}{ Medeni hal } & Evli & 245 & 77,53 \\
\hline & Bekar & 71 & 22,47 \\
\hline \multirow{4}{*}{ Görev } & Doktor & 87 & 27,53 \\
\hline & Ebe & 95 & 30,06 \\
\hline & Hemşire & 109 & 34,49 \\
\hline & Tekniker & 25 & 7,91 \\
\hline \multirow{9}{*}{ Doktor branşı } & Kadın Hast.-Doğum & 27 & 31,40 \\
\hline & Anestezi & 14 & 16,28 \\
\hline & Çocuk & 32 & 37,21 \\
\hline & Çocuk Cerrahi & 3 & 3,49 \\
\hline & Radyoloji & 3 & 3,49 \\
\hline & Dahiliye & 1 & 1,16 \\
\hline & Göz & 1 & 1,16 \\
\hline & Biyokimya & 3 & 3,49 \\
\hline & Mikrobiyoloji & 2 & 2,33 \\
\hline \multirow{2}{*}{ Gelir, TL } & $4000-10000$ & 232 & 73,42 \\
\hline & $>10.000$ & 84 & 26,58 \\
\hline \multirow{2}{*}{ Kronik hastalık } & Var & 67 & 21,20 \\
\hline & Yok & 249 & 78,80 \\
\hline \multirow{2}{*}{ Sigara } & Evet & 99 & 31,33 \\
\hline & Hayır & 217 & 68,67 \\
\hline \multirow{2}{*}{ Alkol } & Evet & 5 & 1,58 \\
\hline & Hayır & 311 & 98,42 \\
\hline
\end{tabular}

Pandemi hastanesinde COVID-19 hastalara doğrudan hizmet sunan grupta duygusal tükenmişlik ve duyarsızlaşma skorunda anlamlı yükseklik, kişisel başarı skorunda anlamlı düşüklük saptanmıştır ( $p=0,014, p=0,003$ ve $p=0,014)$ (Tablo 3 ). Duygusal tükenmişlik, duyarsızlaşma ve kişisel başarı skorları bakımından unvan grupları arasında karşılaştırma normallik testleri sonucuna göre non-parametrik bir test yöntemi olan Kruskal Wallis ile değerlendirilmiştir. Gruplar arasında farklılığın anlamlı bulunduğu duygusal tükenmişlik ve kişisel ba- 
şarı skorları için Dunn post hoc çoklu karşılaştırma testi sonuçlarına göre farklılığı yaratan gruplar tespit edilmiştir. Duygusal tükenmişlik skoru doktor, ebe ve hemşire gruplarında benzer hesaplanmış ve tekniker grubuna göre anlamlı yüksek tespit edilmiştir ( $p=0,008$, Şekil 1$)$. Duyarsızlaşma skoru açısından her dört grup arasında anlamlı fark saptanmamıştır. Doktor grubunun kişisel başarı skoru ebe grubuna göre anlamlı düşük tespit edilirken $(p=0,002)$ hemşire ve tekniker grubuyla anlamlı fark saptanmamıştır (Tablo 4, Şekil 2). Her üç ana branş için yüksek duygusal tükenmişlik ve duyarsızlaşma skoru saptanmıştır. Kadın doğum uzmanları daha yüksek duygusal tükenmişlik ve duyarsızlaşma skoru ile diğer branşlardan anlamlı ayrışmıştır ( $p=0,021$ ve $p=0,038)$. Tüm branşlarda yüksek kişisel başarı skoru saptanmış olup gruplar arası anlamlı fark bulunmamıştır (Tablo 5).

Çalışılan birimler incelendiğinde, duygusal tükenmişlik ve kişisel başarı skorları bakımından gruplar arasında fark gözlenmezken, duyarsızlaşma skorunda gruplar arasında farklılık anlamlı bulunmuştur ( $p=0,039)$. Farklılığı yaratan gruplar incelendiğinde yoğun bakımda çalışanlar ile poliklinikte çalışanlar duyarsızlaşma skoru bakımından en yüksek ve en düşük skorları almışlardır (Tablo 6, Şekil 3).

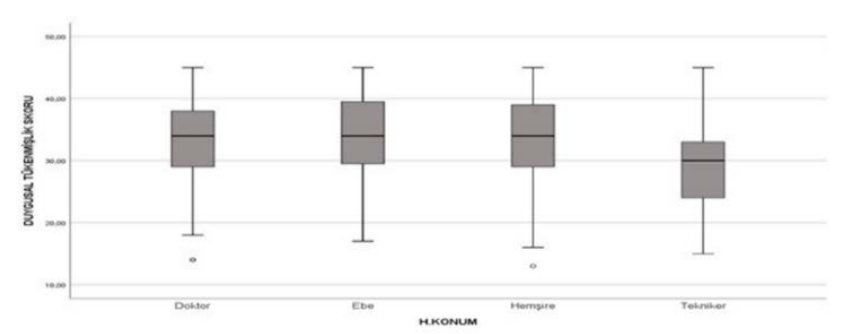

Şekil 1. Katılımcıların duygusal tükenmişlik skorlarının mesleklere göre dağılımı

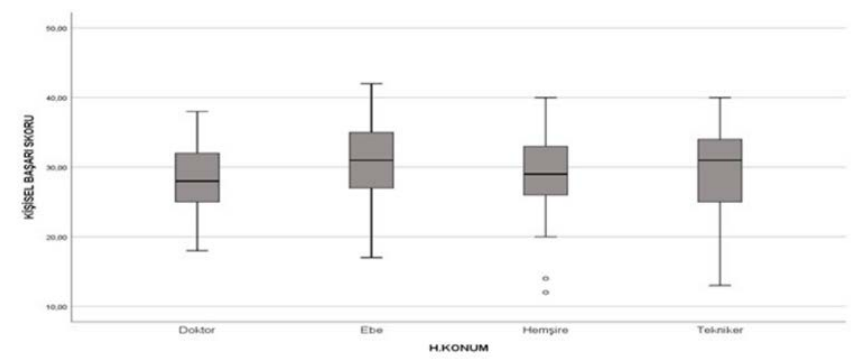

Şekil 2. Katılımcıların kişisel başarı skorlarının mesleklere göre dağılımı
Tablo 2. İş ve iş yeri ile ilgili özellikler

\begin{tabular}{|c|c|c|c|}
\hline & & $n$ & $\%$ \\
\hline \multirow{7}{*}{ Çalışılan birim } & Acil Servis & 20 & 8.70 \\
\hline & Yataklı servis & 68 & 29.57 \\
\hline & Yoğun bakım & 29 & 12.61 \\
\hline & Ameliyathane & 34 & 14.78 \\
\hline & Doğumhane & 56 & 24.35 \\
\hline & Poliklinik & 17 & 7.39 \\
\hline & Diğer & 6 & 2.61 \\
\hline \multirow{3}{*}{ Hastanede çalışma süresi } & 1-5 Yıl & 126 & 39.87 \\
\hline & 5-10 Yıl & 101 & 31.96 \\
\hline & $>10 \mathrm{yll}$ & 89 & 28.16 \\
\hline \multirow{4}{*}{ Toplam çalışma süresi } & $1-6$ yıl & 67 & 21.27 \\
\hline & 7-10 yıl & 48 & 15.24 \\
\hline & 11-17 yıl & 97 & 30.79 \\
\hline & $>18$ yıl & 103 & 32.38 \\
\hline \multirow{2}{*}{$\begin{array}{l}\text { Mesleğinizi isteyerek mi } \\
\text { seçtiniz? }\end{array}$} & Evet & 210 & 67.10 \\
\hline & Hayır & 103 & 32.90 \\
\hline \multirow{3}{*}{$\begin{array}{l}\text { Mesleğiniz beklentilerinizi } \\
\text { karşıladı mı? }\end{array}$} & Evet & 12 & 3.81 \\
\hline & Kısmen & 125 & 39.68 \\
\hline & Hayır & 178 & 56.51 \\
\hline \multirow{3}{*}{$\begin{array}{l}\text { Mesleğiniz hakettiği değeri } \\
\text { görüyor mu? }\end{array}$} & Evet & 1 & 0.32 \\
\hline & Kısmen & 30 & 9.49 \\
\hline & Hayır & 285 & 90.19 \\
\hline \multirow{4}{*}{$\begin{array}{l}\text { Mesleğinizi yapmaya mo- } \\
\text { tive eden şey? }\end{array}$} & Mesleği sevme & 83 & 26.27 \\
\hline & Ekonomik nedenler & 208 & 65.82 \\
\hline & Toplumsal nedenler & 12 & 3.80 \\
\hline & Diğer & 13 & 4.11 \\
\hline \multirow{4}{*}{$\begin{array}{l}\text { Olumsuz hasta davranışı ile } \\
\text { karşılaşma sıklığı }\end{array}$} & Nadir & 38 & 12.03 \\
\hline & Ara sıra & 115 & 36.39 \\
\hline & Sık & 97 & 30.70 \\
\hline & Çok sık & 66 & 20.89 \\
\hline \multirow{5}{*}{ Günlük hasta sayısı, n } & $1-9$ & 73 & 23.10 \\
\hline & $10-19$ & 49 & 15.51 \\
\hline & $20-29$ & 44 & 13.92 \\
\hline & $30-39$ & 49 & 15.51 \\
\hline & $>40$ & 101 & 31.96 \\
\hline \multirow{2}{*}{$\begin{array}{l}\text { Gece/ek mesai yapıyor mu- } \\
\text { sunuz? }\end{array}$} & Evet & 265 & 83.86 \\
\hline & Hayır & 51 & 16.14 \\
\hline \multirow{3}{*}{ Fiziki koşullar yeterli mi } & Evet & 9 & 2.85 \\
\hline & Kısmen & 107 & 33.86 \\
\hline & Hayır & 200 & 63.29 \\
\hline \multirow{2}{*}{$\begin{array}{l}\text { COVID-19 (+) hasta bakı- } \\
\text { mında görevli misiniz? }\end{array}$} & Evet & 185 & 58.54 \\
\hline & Hayır & 131 & 41.46 \\
\hline
\end{tabular}


Tablo 3. Sosyodemografik veriler, iş ve iş yeri ile ilgili değişkenlere göre skorlar

\begin{tabular}{|c|c|c|c|c|c|c|c|c|c|c|}
\hline & & \multicolumn{3}{|c|}{ Duygusal tükenmişlik skoru } & \multicolumn{2}{|c|}{ Duyarsızlaşma skoru } & \multicolumn{4}{|c|}{ Kişisel başarı skoru } \\
\hline & & Ort.tstd. & $\begin{array}{l}\text { Medyan- } \\
\text { Aralık }\end{array}$ & $\mathbf{p}$ & Ort.tstd. & $\begin{array}{l}\text { Medyan- } \\
\text { Aralık }\end{array}$ & p & Ort.tstd. & Medyan-Aralık & $p$ \\
\hline \multirow{3}{*}{ Yaş, yıl } & $<29$ & $33,81 \pm 7,34$ & $34-26$ & \multirow{3}{*}{0,412} & $13,35 \pm 4,12^{\mathrm{a}}$ & $14-18$ & \multirow{3}{*}{$0,001 *$} & $27,98 \pm 6,02^{\mathrm{a}}$ & \begin{tabular}{|l|}
$27-26$ \\
\end{tabular} & \multirow{3}{*}{$0,015^{*}$} \\
\hline & $29-39$ & $33,53 \pm 6,77$ & $34-31$ & & $11,97 \pm 4,48^{b}$ & $12-20$ & & $29,08 \pm 4,65^{\text {ab }}$ & $29-25$ & \\
\hline & $>39$ & $32,49 \pm 7,95$ & $33-32$ & & $10,73 \pm 4,80^{b}$ & $10-17$ & & $30,35 \pm 5,52^{\mathbf{b}}$ & $30-29$ & \\
\hline \multirow{2}{*}{ Cinsiyet } & Erkek & $31,69 \pm 7,56$ & $32-31$ & \multirow{2}{*}{0,043} & $12,28 \pm 4,13$ & $12-16$ & \multirow{2}{*}{0,104} & $27,92 \pm 5,19$ & $28-25$ & \multirow{2}{*}{0,003} \\
\hline & Kadın & $33,75 \pm 7,18$ & $34-32$ & & $11,55 \pm 4,79$ & $11-20$ & & $29,91 \pm 5,26$ & $30-30$ & \\
\hline \multirow{2}{*}{ Medeni hal } & Evli & $33,07 \pm 7,21$ & $33-32$ & \multirow{2}{*}{0,442} & $11,55 \pm 4,65$ & $11-20$ & \multirow{2}{*}{0,114} & $29,47 \pm 5,14$ & $30-27$ & \multirow{2}{*}{0,552} \\
\hline & Bekar & $33,59 \pm 7,8$ & $35-31$ & & $12,44 \pm 4,52$ & $13-18$ & & $29 \pm 5,87$ & \begin{tabular}{|l|}
$29-30$ \\
\end{tabular} & \\
\hline \multirow[t]{2}{*}{ Gelir, TL } & $\begin{array}{l}4000- \\
10000\end{array}$ & $33,22 \pm 7,4$ & $33,5-32$ & \multirow[t]{2}{*}{0,947} & $11,42 \pm 4,67$ & $11-20$ & \multirow[t]{2}{*}{0,025} & $29,7 \pm 5,51$ & $30-30$ & 0,023 \\
\hline & $>10.000$ & $33,08 \pm 7,19$ & $34-31$ & & $12,64 \pm 4,41$ & $12-17$ & & $28,44 \pm 4,61$ & $28,5-20$ & \\
\hline & Var & $32,31 \pm 7,32$ & $34-28$ & & $11,42 \pm 4,64$ & $11-18$ & & $29,58 \pm 5,05$ & \begin{tabular}{|l|}
$30-20$ \\
\end{tabular} & \\
\hline Kronik hastalık & Yok & $33,42 \pm 7,34$ & $34-32$ & 0,341 & $11,84 \pm 4,63$ & $12-20$ & 0,480 & $29,31 \pm 5,38$ & $30-30$ & 0,924 \\
\hline Sigara & Evet & $33,37 \pm 7,57$ & $34-32$ & $0693 *$ & $11,72 \pm 4,73$ & $12-20$ & $0890 *$ & $30,36 \pm 5,3$ & 31-29 & $0024 *$ \\
\hline SIgara & Hayır & $33,10 \pm 7,24$ & $34-31$ & $0,693^{\circ}$ & $11,76 \pm 4,59$ & $12-18$ & $0,890^{\circ}$ & $28,91 \pm 5,26$ & $29-28$ & $0,0<4^{*}$ \\
\hline alkel & Evet & $37 \pm 3,67$ & $39-7$ & & $11,2 \pm 2,68$ & $11-7$ & & $24,6 \pm 3,65$ & $23-9$ & $0023 *$ \\
\hline Alkol & Hayır & $33,12 \pm 7,37$ & $34-32$ & $0,229^{*}$ & $11,76 \pm 4,65$ & $12-20$ & $0,857^{*}$ & $29,44 \pm 5,3$ & \begin{tabular}{|l|}
$30-30$ \\
\end{tabular} & $0,023^{\circ}$ \\
\hline & 1-5 Yıl & $34,15 \pm 7,13^{a}$ & $34-31$ & & $12,36 \pm 4,37^{\mathrm{a}}$ & $12-18$ & & $29,01 \pm 5,15$ & $29-26$ & \\
\hline $\begin{array}{l}\text { Hastanede ça- } \\
\text { lusma süresi }\end{array}$ & 5-10 YII & $33,33 \pm 7,8^{\mathrm{ab}}$ & $35-31$ & $0,047^{*}$ & $11,95 \pm 4,87^{\mathrm{a}}$ & $12-20$ & $0,025 *$ & $29,31 \pm 5,44$ & \begin{tabular}{|l|}
$29-28$ \\
\end{tabular} & $0,451^{*}$ \\
\hline & $>10 \mathrm{yıl}$ & $31,65 \pm 6,9^{b}$ & $32-32$ & & $10,65 \pm 4,55^{b}$ & $10-18$ & & $29,93 \pm 5,38$ & $30-29$ & \\
\hline & 1-6 YII & $34,19 \pm 6,8$ & $34-30$ & & $13,07 \pm 4,35$ & $14-20^{\mathrm{a}}$ & & $27,66 \pm 5,65$ & $27-26^{a}$ & \\
\hline Toplam çalışma & 7-10 YıI & $31,48 \pm 7,35$ & $31,5-26$ & 0184 & $12,31 \pm 4,12$ & $12-17^{a}$ & & $29,1 \pm 5,11$ & $29,5-28^{\text {ab }}$ & \\
\hline süresi & 11-17 YII & $33,78 \pm 7,1$ & $34-31$ & 0,184 & $11,89 \pm 4,91$ & $11-18^{\mathrm{ab}}$ & 0,003 & $29,33 \pm 4,76$ & $30-23^{\text {ab }}$ & 0,004 \\
\hline & $>18 \mathrm{YII}$ & $32,71 \pm 7,86$ & $33,5-32$ & & $10,42 \pm 4,5$ & $9-18^{b}$ & & $30,68 \pm 5,44$ & $31-29^{b}$ & \\
\hline Mesleğinizi iste- & Evet & $32,82 \pm 7,39$ & $33-31$ & & $11,79 \pm 4,7$ & $12-20$ & & $29,59 \pm 5,03$ & \begin{tabular}{|l|}
$30-25$ \\
\end{tabular} & \\
\hline $\begin{array}{l}\text { yerek mi seçti- } \\
\text { niz? }\end{array}$ & Hayır & $33,85 \pm 7,18$ & $34-32$ & 0,207 & $11,59 \pm 4,4$ & $12-18$ & 0,779 & $28,99 \pm 5,78$ & $30-26$ & 0,667 \\
\hline Mesleğiniz bek- & Evet & $26,42 \pm 6,47$ & $26-24^{a}$ & & $8,83 \pm 3,1$ & $8-8$ & & $31,75 \pm 5,01$ & $32-18$ & \\
\hline lentilerinizi kar- & Kısmen & $30,86 \pm 6,79$ & $32-31^{b}$ & 0,032 & $11,73 \pm 4,6$ & $12-18$ & 0,074 & $29,58 \pm 5,1$ & $30-25$ & 0,226 \\
\hline şıladı mı? & Hayır & $35,3 \pm 7,02$ & $35-32^{b}$ & & $11,97 \pm 4,69$ & $12-20$ & & $29,11 \pm 5,42$ & \begin{tabular}{|l|}
$29-30$ \\
\end{tabular} & \\
\hline Mesleğiniz ha- & Evet & $22,00 \pm N A$ & $22-0$ & & $5 \pm N A$ & $5-0$ & & $33 \pm N A$ & $33-0$ & \\
\hline kettiği değeri & Kısmen & $29,47 \pm 6,48$ & $30,5-26$ & NA & $10,83 \pm 3,93$ & $10-14$ & NA & $28,6 \pm 6,53$ & $30-25$ & NA \\
\hline görüyor mu? & Hayır & $33,61 \pm 7,3$ & $34-32$ & & $11,87 \pm 4,68$ & $12-20$ & & $29,43 \pm 5,18$ & $30-30$ & \\
\hline & Sevme & $29,89 \pm 7,46$ & $31-32^{a}$ & & $10,96 \pm 4,44$ & $10-18$ & & $29,88 \pm 4,88$ & $30-22^{a}$ & \\
\hline Mesleğinizi yap- & Ekonomik & $34,21 \pm 7,01$ & $34-31^{b}$ & & $11,83 \pm 4,52$ & $12-20$ & & $29,49 \pm 5,32$ & $30-28^{a}$ & \\
\hline maya motive & Toplumsal & $35,33 \pm 6,97$ & $36-19^{b}$ & $<0,001$ & $13,33 \pm 5,55$ & $13,5-18$ & 0,134 & $27,75 \pm 5,88$ & $27,5-21^{\text {ab }}$ & 0,044 \\
\hline & Diğer & $35,77 \pm 5,97$ & $35-16^{b}$ & & $13,92 \pm 5,92$ & $15-17$ & & $25,62 \pm 6,04$ & $25-22^{b}$ & \\
\hline Olumsuz hasta & Nadir & $29,13 \pm 7,41$ & $30-31^{\mathrm{a}}$ & & $8,63 \pm 4,14$ & $7,5-20^{a}$ & & $30,13 \pm 6,52$ & $32-28$ & \\
\hline davranışı ile & Ara sıra & $31,08 \pm 6,88$ & $32-30^{a}$ & & $11,1 \pm 4,29$ & $11-18^{b}$ & $<0.001$ & $28,97 \pm 5,58$ & \begin{tabular}{|l|}
$29-29$ \\
\end{tabular} & 0.376 \\
\hline karşılaşma sık- & Sık & $35,63 \pm 6,65$ & $36-31^{b}$ & $<0,001$ & $12,51 \pm 4,57$ & $13-17^{b}$ & $<0,001$ & $29,03 \pm 4,62$ & $29-23$ & $0,3 / 6$ \\
\hline & Çok Sık & $35,59 \pm 7$ & $36-32^{b}$ & & $13,55 \pm 4,51$ & $13-18^{b}$ & & $30,11 \pm 4,98$ & $30,5-24$ & \\
\hline & $1-9$ & $33,47 \pm 6,8$ & $34-28$ & & $11,71 \pm 4,33$ & $12-18$ & & $28,21 \pm 5,96$ & $28-27$ & \\
\hline & $10-19$ & $31,51 \pm 7,57$ & $32-30$ & & $10,84 \pm 4,98$ & $10-20$ & & $30,71 \pm 5,32$ & $32-20$ & \\
\hline Günlük hasta & $20-29$ & $32 \pm 8,18$ & $33-31$ & 0,266 & $10,66 \pm 4,07$ & $10,5-15$ & 0,118 & $28,32 \pm 5,63$ & $27,5-26$ & 0,101 \\
\hline & $30-39$ & $34,47 \pm 7,34$ & $35-32$ & & $12,63 \pm 4,41$ & $12-18$ & & $29,47 \pm 5,39$ & $30-24$ & \\
\hline & $>40$ & $33,68 \pm 7,15$ & $34-31$ & & $12,26 \pm 4,9$ & $12-17$ & & $29,95 \pm 4,4$ & $30-22$ & \\
\hline Gece/ek mesai & Evet & $33,74 \pm 7,1$ & $34-31$ & & $12,05 \pm 4,69$ & $12-20$ & & $29,22 \pm 5,27$ & $30-30$ & \\
\hline $\begin{array}{l}\text { yapıyor musu- } \\
\text { nuz? }\end{array}$ & Hayır & $30,31 \pm 7,92$ & $31-32$ & $0,004^{*}$ & $10,2 \pm 3,95$ & $10-13$ & $0,012^{*}$ & $30,14 \pm 5,5$ & $30-23$ & $0,251^{*}$ \\
\hline & Evet & $27,22 \pm 9,52$ & $23-23^{a}$ & & $10,44 \pm 4,3$ & $10-12$ & & $29,44 \pm 6,35$ & \begin{tabular}{|l|}
$29-17$ \\
\end{tabular} & \\
\hline Fiziki koşullar & Kısmen & $31,56 \pm 7,26$ & $31-29^{b}$ & $<0,001$ & $11 \pm 4,6$ & $10-18$ & 0,065 & $29,5 \pm 5,19$ & $30-27$ & 0,941 \\
\hline yeteril mi? & Hayır & $34,32 \pm 7,01$ & $35-32^{b}$ & & $12,21 \pm 4,61$ & $12-20$ & & $29,29 \pm 5,35$ & $30-28$ & \\
\hline $\begin{array}{ll}\text { COVID-19 } & (+)\end{array}$ & Evet & $34,03 \pm 7,17$ & $34-31$ & & $12,42 \pm 4,83$ & $12-20$ & & $28,77 \pm 5,38$ & \begin{tabular}{|l|}
$29-27$ \\
\end{tabular} & \\
\hline $\begin{array}{l}\text { hasta bakı- } \\
\text { mında görevli } \\
\text { misiniz? }\end{array}$ & Hayır & $31,98 \pm 7,43$ & $32-32$ & 0,014 & $10,8 \pm 4,17$ & $10-18$ & 0,003 & $30,2 \pm 5,11$ & $30-30$ & 0,014 \\
\hline
\end{tabular}

“*” ile belirtilenler parametrik testlerle, diğerleri non-parametrik testlerle analiz edildi.

Tablo 4. Mesleklere göre Skorlar

\begin{tabular}{|c|c|c|c|c|c|c|}
\hline & \multicolumn{2}{|c|}{ Duygusal tükenmişlik skoru } & \multicolumn{2}{|c|}{ Duyarsızlaşma skoru } & \multicolumn{2}{|c|}{ Kişisel başarı skoru } \\
\hline & Ort. \pm std. & Medyan-Aralık & Ort. \pm std. & Medyan-Aralık & Ort. \pm std. & Medyan-Aralık \\
\hline Doktor & $33,33 \pm 7,24$ & $34-31^{a}$ & $12,75 \pm 4,41$ & $12-17$ & $28,41 \pm 4,54$ & $28-20^{\mathrm{a}}$ \\
\hline Ebe & $33,96 \pm 7,28$ & $34-28^{a}$ & $11,52 \pm 5,06$ & $11-20$ & $30,63 \pm 5,45$ & $31-25^{\mathrm{b}}$ \\
\hline Hemşire & $33,3 \pm 7,25$ & $34-32^{a}$ & $11,32 \pm 4,31$ & $11-18$ & $29,11 \pm 5,11$ & $29-28^{\text {ab }}$ \\
\hline Anestezi teknikeri & $29,2 \pm 7,46$ & $30-30^{b}$ & $11 \pm 4,74$ & $10-14$ & $28,96 \pm 7,24$ & $31-27^{\mathrm{ab}}$ \\
\hline p & \multicolumn{2}{|l|}{0,008} & \multicolumn{2}{|l|}{0,431} & \multicolumn{2}{|l|}{0,002} \\
\hline
\end{tabular}

${ }^{a} v^{b}$ gibi indisler için: aynı harfle gösterilen ortancalar birbirleriyle aynı farklı indislerle gösterilenler ise istatistiksel olarak farklıdır. 
Tablo 5. Branşlara göre skorlar

\begin{tabular}{|c|c|c|c|c|c|c|c|}
\hline & \multirow[b]{2}{*}{$\mathbf{n}$} & \multicolumn{2}{|c|}{ Duygusal tükenmişlik skoru } & \multicolumn{2}{|c|}{ Duyarsızlaşma skoru } & \multicolumn{2}{|c|}{ Kişisel başarı skoru } \\
\hline & & Ort..tstd. & Medyan-Aralık & Ort. \pm std. & Medyan-Aralık & Ort..tstd. & $\begin{array}{l}\text { Medyan-Ara- } \\
\text { lık }\end{array}$ \\
\hline Kadın hast-Doğum & 27 & $35,89 \pm 7,05$ & $38-26^{a}$ & $14,56 \pm 4,15^{a}$ & $16-16$ & $29,3 \pm 4,57$ & $29-16$ \\
\hline Anestezi & 14 & $33,5 \pm 5,71$ & $35-22^{\mathrm{ab}}$ & $13 \pm 4,35^{\text {ab }}$ & $14-13$ & $26,86 \pm 4,85$ & $27,5-19$ \\
\hline Çocuk & 26 & $33,31 \pm 6,73$ & $33,5-31^{\text {ab }}$ & $12,08 \pm 4,05^{\mathrm{ab}}$ & $11,5-15$ & $27,92 \pm 3,94$ & $27-14$ \\
\hline Diğer & 19 & $29,16 \pm 7,75$ & $29-31^{b}$ & $10,95 \pm 4,73^{b}$ & $10-17$ & $28,95 \pm 5,09$ & $30-18$ \\
\hline $\mathbf{p}$ & & \multicolumn{2}{|l|}{0.021} & \multicolumn{2}{|l|}{$0.038 *$} & \multicolumn{2}{|l|}{$0.367^{*}$} \\
\hline
\end{tabular}

${ }^{a, b}$ ve $^{\text {ab }}$ gibi indisler için: aynı harfle gösterilen ortancalar birbirleriyle aynı farklı indislerle gösterilenler ise istatistiksel olarak farklıdır. "*” ile belirtilenler parametrik testlerle, diğerleri non-parametrik testlerle analiz edildi.

Tablo 6. Çalışılan birimlere göre skorlar

\begin{tabular}{|c|c|c|c|c|c|c|c|}
\hline & & \multicolumn{2}{|c|}{ Duygusal tükenmişlik skoru } & \multicolumn{2}{|c|}{ Duyarsızlaşma skoru } & \multicolumn{2}{|c|}{ Kişisel başarı skoru } \\
\hline & $\mathrm{n}$ & Ort. \pm std. & Medyan-Aralık & Ort. \pm std. & Medyan-Aralık & Ort. \pm std. & Medyan-Aralık \\
\hline Acil servis & 20 & $35,35 \pm 6,43$ & $35-22$ & $12,4 \pm 4,15$ & $11-15^{\text {ab }}$ & $29,15 \pm 4,5$ & $30-17$ \\
\hline Yataklı servis & 68 & $33,03 \pm 7,92$ & $33-32$ & $11,31 \pm 4,54$ & $11-18^{\mathrm{ab}}$ & $29,91 \pm 5,45$ & $30-26$ \\
\hline Yoğun bakım & 29 & $34,17 \pm 6,76$ & $34-23$ & $12 \pm 3,17$ & $13-11^{a}$ & $28,69 \pm 5,52$ & $28-30$ \\
\hline Ameliyathane & 34 & $34,53 \pm 6,81$ & $35-27$ & $10 \pm 4,88$ & $9-18^{\mathrm{ab}}$ & $29,53 \pm 5,5$ & $28,5-19$ \\
\hline Doğumhane & 56 & $32,57 \pm 7,07$ & $32,5-30$ & $12,5 \pm 4,96$ & $14-20^{\text {ab }}$ & $29,21 \pm 6,04$ & $30-27$ \\
\hline Poliklinik & 17 & $31,18 \pm 8,54$ & $31-25$ & $9,18 \pm 5,36$ & $6-18^{b}$ & $32,94 \pm 4,53$ & $34-14$ \\
\hline Diğer & 6 & $26 \pm 6,51$ & 24-18 & $9 \pm 4,1$ & $8-11^{a b}$ & $31,17 \pm 6,18$ & $32,5-17$ \\
\hline \multicolumn{2}{|l|}{$p$} & \multicolumn{2}{|l|}{0,096} & \multicolumn{2}{|l|}{0,039} & \multicolumn{2}{|l|}{0,239} \\
\hline
\end{tabular}

${ }^{\mathbf{a}, \mathbf{b}} \mathrm{ve}^{\mathrm{ab}}$ gibi indisler için: aynı harfle gösterilen ortancalar birbirleriyle aynı farklı indislerle gösterilenler ise istatistiksel olarak farklıdır.

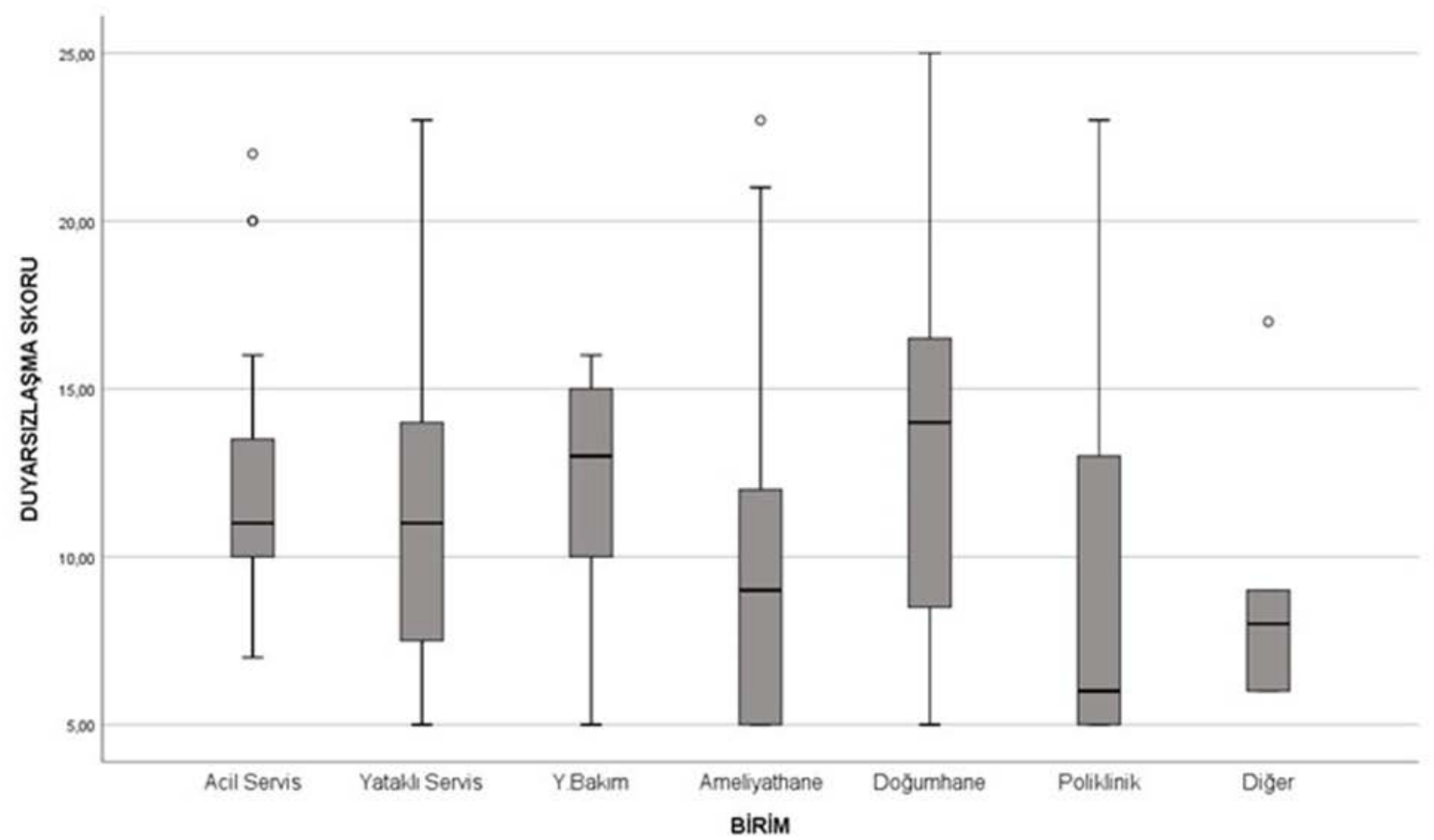

Şekil 3. Katılımcıların duyarsızlaşma skorlarının çalışılan birimlere göre dağılımı

\section{Tartışma}

Freudenberger'e göre tükenmişlik sendromu bir meslek hastalığıdır (1). COVID-19 pandemisinin sağlık çalışanları arasında tükenmişlik sendromunu arttırdığı belirtilmiştir (14). Finlandiya merkezli sağlık profesyonellerini kapsayan bir çalışmada sosyo-demografik özellikler ile tükenmişlik seviyesi arasında güçlü ilişki saptanmamış; tükenmişlik send- romunda, kadınlarda eğitim ve sosyoekonomik düzeyle, erkeklerde evlilik durumuyla paralellik gösteren artış bildirilmiştir (15). Çalışmalarda duygusal tükenmişliğin genç çalışanlarda (30 yaş ve altında) yaşlılara göre \%12,6 ( $p=0,19)$, kadınlarda erkeklere göre \%13 $(p=0,38)$ oranında daha fazla görüldüğü bildirilmiştir $(16,17,18)$. Medeni hal ile duygusal tükenmişlik sendromu arasında anlamlı ilişki saptamayan $(13,16,19)$ ya da doğru orantı bildiren $(20)$ çalışmalar mevcuttur. Ayrıca duyarsızlaşma skoru ile yaş ve medeni hal 
arasında anlamlı ilişki saptanmazken erkeklerde kadınlardan \%13 fazla yüksek duyarsızlaşma skoru bildirilmiştir $(13,16)$. Kişisel başarı skorun gençlerde yaşlılara göre \%10,6 $(p=0,24)$ ve kadınlarda erkeklere göre $\% 17,8(p=0,20)$ düşük bulunmuştur (16).

Çalışmalarda duyarsızlaşma skoru gençlerde yaşlılara göre anlamlı yüksek duyarsızlaşma skoru ve yüksek duygusal tükenmişlik skoru bildirilmiştir (14,20). 8959 ebeyi içeren bir meta-analize göre genç yaşta olmak ve bekar olmak ebelerde yüksek tükenmişlik skoruyla ilişkilendirilmiştir (21). Çalışmamızda yaş ile duygusal tükenmişlik skoru arasında anlamlı ilişki saptanmazken; gençlerde yaşlılara oranla duyarsızlaşma skoru anlamlı yüksek, kişisel başarı skoru anlamlı düşük çıkmıştır. Hayat deneyimlerinin az olması ve zorlu olaylarla başa çıkabilme yetisi için deneyime ihtiyaç duyulması, gençlerde duyarsızlaşma skoru yüksekliğinin nedeni olabilir. Mesleki deneyim ile artan özgüven duygusu gençlerde zamanla oluşacağından yetersizlik hissi yaşlılara oranla daha fazla görülüyor olabilir. Zira, yayınlar yaşlı çalışanlarda sorunlara daha kolay çözüm bulabilme yetenekleri ve meslekten beklentilerinde daha gerçekçi olmaları nedeniyle gençlere oranla daha az tükenmişlik durumu bildirmiştir (22). Erkeklerde daha yüksek duyarsızlaşma ve kişisel başarı skorları bildiren literatür verilerinin aksine (16) çalışmamızda duyarsızlaşma skorunda cinsiyet açısından anlamlı fark saptanmamıştır. Literatürde her ne kadar anlamlı fark olmasa da kadınlarda daha yüksek duygusal tükenmişlik skorları bildiren çalışmaların $(13,16,17,19,20)$ aksine çalışmamızda kadınlarda duygusal tükenmişlik ve kişisel başarı skorları anlamlı yüksek bulunmuştur. Bu durum kadınlarda her ne kadar duygusal tükenmişlik daha sık görülse de mesleklerini yaparlarken özgüvenlerinin yerinde olduğunun işareti olabilir.

Hasta sayısı ve maruziyet sıklığı, uzun çalışma saatleri, aşırı iş yükü, kronik ya da ölümcül hastalara hizmet verme, meslekten beklentilerinin karşılanmamış olması, çoklu görevlendirme, görev tanımının net olmaması,personel ve kaynak eksikliği, düşük kazanç, olumsuz fiziki koşullar ve acil serviste çalışma tükenmişlik sendromuna eğilimi arttıran faktörler olarak bildirilmiştir $(13,14,16,19,20,23)$. Haftada bakılan hasta sayısındaki her 10 artışın tükenmişlik sendromu riskini 1,25 kat arttırdığı saptanmıştır (20). Sigara kullanımı, mesleğin toplumdan yeterli ilgiyi görmemesi, mesleğin beklentileri karşılamaması ile duygusal tükenmişlik arasında pozitif ilişki saptanmış ve mesleki tatminin azalması ile yüksek tükenmişlik arasında istatistiksel olarak anlamlı birliktelik tespit edilmiştir (13). Çalışmamızda literatürün aksine günlük hasta sayısının fazla oluşunun duygusal tükenmişlik, duyarsızlaşma ve kişisel başarı skoru üzerinde etkisi olmadığı ancak gece/ek mesai sürelerinin varlığının artmış duygusal tükenmişlik ve duyarsızlaşma skoruna eşlik ettiği saptandı. Bu durum, gündüz mesaide fazla hasta bakılsa bile, gece/ek mesai yapmanın (hasta sayısından bağımsız) duygusal tükenmişlik üzerine olumsuz etkisinin daha ön planda olduğu şeklinde yorumlanabilir. Çalışma- mızda yoğun bakımda çalışanlarda anlamlı yüksek, poliklinik çalışanlarda ise anlamlı düşük duyarsızlaşma skoru tespit edilmiştir. Bu durum yoğun bakımdaki hasta yatışının uzun olması ve yoğun iş yüküne rağmen hasta kayıplarının daha sık yaşanmasıyla açıklanabilir. Çalışmamızda literatürle uyumlu olarak olumsuz hasta davranışlarının sıklığı ve kötü fiziki koşulların varlığı ile duygusal tükenmişlik arasında anlamlı ilişki saptanmıştır. Çalışmamızda doğru meslek seçimi yapmadıklarını düşünen grupta literatürle uyumlu olarak anlamlı yüksek tükenmişlik skoru tespit edilmiştir.

Tükenmişlik tüm mesleklerde oluşabilir ancak doktorlarda sıklık daha yüksek görünmektedir (8). Çalışmalarda doktorlarda \%35,1-37,9, normal popülasyondan seçilen kontrol grubunda ise $\% 27,8$ oranında tükenmişlik sendromu tespit edilmiştir $(p<0.001)(10,18)$. Özellikle hizmet sunumunda ön saflarda bulunan aile hekimleri ve acil servis doktorlarında oran daha yüksek saptanmıştır (24). Uzman hekimler duygusal tükenmişlik sendromu görülme sıklığı açısından seviyelere ayrılmış, genel cerrahi, anestezi, obstetri ve jinekoloji ve ortopedi branşlarında $\% 42,5$ ile en yüksek oranda tükenmişlik sendromu görüldüğü tespit edilmiştir. Metaregresyon analizinde her üç grup arasında anlamlı fark saptanmamıştır $(p=0,17)(10)$. De Hert S'nin çalışmasında sağlık çalışanlarının ve özellikle cerrahi kliniklerin tükenmişlik açısından risk altında olduğu saptanmıştır (8). Bu durum olumsuz bireysel davranışların (madde kullanımı, ilişkilerde bozulma hatta intihar girişimi) yanında düşük hasta tatmini, sağlık hizmet kalitesinde bozulma ve potansiyel olarak malpraktise kadar uzanabilen ve sonuçta hem çalışan hem de kuruma ciddi maliyetlere mal olabilecek tıbbi hatlara neden olabilmektedir (8). Jinekoloji ve obstetri hastanesinde çalışan doktorların uzmanlık alt grupları kıyaslandığında duygusal tükenmişlik ve duyarsızlaşma skorları arasında anlamlı fark saptanmazken en yüksek duyarsızlaşma skoru kadın doğum grubunda saptanmıştır (13). 42473 doktoru içeren 47 çalışmalık bir sistemik derleme ve metaanaliz sonuçlarına göre doktorlarda duygusal tükenmişlik sendromu varlığının hastanın sağlık hizmetine duyduğu güvende iki kat azalışla ilişki olduğu, tükenmişlik sendromunun her üç alt bileşeni ile hasta güven problemlerinde anlamlı artış saptandığı, duyarsızlaşmanın yetersiz profesyonel sağlık hizmeti sunumu riskinde üç kat artışa neden olduğu, duygusal tükenmişlik ve kişisel başarı düşüklüğü yetersiz profesyonel sağlık hizmeti sunumu riskinde 2,5 katın üzerinde artışa neden olduğu ve tükenmişlik sendromunun hasta memnuniyetinde iki kat düşüş ile ilişkili olduğu, duyarsızlaşmanın hasta memnuniyetinde 4,5 kat düşüşle ilişkili olduğu, kişisel başarı düşüklüğünün hasta memnuniyetinde 2 kat düşüşle ilişkili olduğu ve duygusal tükenmişliğin hasta memnuniyetinde anlamlı düşüşe neden olduğu bildirilmiştir (11). Çalışmamızda tüm gruplarda yüksek duygusal tükenmişlik skoru saptanmıştır. Duygusal tükenmişlik skorları doktor, ebe ve hemşire grubunda benzer iken anestezi teknikerlerinde anlamlı düşük saptanmıştır. Bu durum anestezi teknisyenlerinde daha az hasta sayısı ve nispeten daha iyi 
fiziki koşullara sahip olmaları ile ilişkilendirilebilinir. Ayrıca, kadın hastalıkları ve doğum uzmanlarında diğer uzman hekimlerden anlamlı daha yüksek duygusal tükenmişlik ve duyarsızlaşma skoru tespit edilmiştir. Bu durum kadın hastalıkları ve doğum uzmanlarının, bölgemizin yüksek doğurganlık hızı ve yetersiz sağlık alt yapısı sonucu oluşan ağır iş yükünü olumsuz etkilerini yaşamalarından kaynaklı olabilir. COVID-19 hastalarına hizmet sunan grupta anlamlı yüksek tükenmişlik düzeyi tespit edilmiştir (14). Çalışmamızda COViD-19 hastalarına doğrudan hizmet sunan çalışanlarda, geri planda olanlara oranla istatistiksel olarak anlamlı yüksek duygusal tükenmişlik ve duyarsızlaşma skoru; anlamlı düşük kişisel başarı skoru tespit edilmiştir. Bu durum çalışmamıza konu edilen tüm gruplar arasında duygusal tükenmişlik sendromu tanısı için üç alt skorda aranan kriterlerin bir arada karşılandığı yegane grup olduğu için oldukça anlamlıdır. COVID-19 pandemisinin sağlık sistemi üzerindeki yıkıcı etkilerinden birisi de duygusal tükenmişlik sendromunda anlamlı artışa neden olmasıdır. Tükenmişlik durumunun çalışanlar, sağlık kurumu ve hastalar için ciddi zararlarının olduğu kabul edilmeli, risk faktörleri tanımlanmalı ve ileride oluşabilecek zararlardan korunmak için önleyici çaIışmalar yapılmalıdır (25).

\section{Sonuç}

Tükenmişlik sendromu sağlık çalışanları arasında yüksek oranda görülmektedir. Kadın hastalıkları doğum kliniklerinin tükenmişlik sendromu açısından halihazırda var olan yüksek risklerinin COVID-19 pandemisi ile daha da arttığı ortaya çıkmıştır. Çalışmamızda yaş ve mesleki tecrübe arttıkça duygusal tükenmişlikle başa çıkabilme kabiliyetinde artış tespit edilmiştir. Olumsuz hasta davranışlar ve artan hasta yükü, fazla mesai yapma, uygunsuz fiziki koşullar ve en önemlisi pandeminin varlığı ile tükenmişlik sendromu sıklığı arasında anlamlı birliktelik tespit edilmiştir.

Tükenmişlik sendromu hem çalışanın ruh ve beden sağlığını bozarak hem de sunulan sağlık hizmetinde hasta memnuniyeti ve verimliğin azalmasına neden olarak sisteme ciddi yükler getirmektedir. İçinde bulunduğumuz pandemi döneminde kaynakları daha verimli kulllanıması gerektiğini düşünerek tespit ettiğimiz tükenmişlik sendromu risk faktörlerinin sağlık politikaları yapıcıları tarafından dikkate alınması gerektiğini düşünüyoruz.

Etik onam: Çalışma için Sağlık Bilimleri Üniversitesi Gazi Yaşargil Eğitim Ve Araştırma Hastanesi Klinik Araştırmalar Etik Kurulundan etik onayı alındı (08/10/2021 tarih ve 893 sayılı yazı).

\section{Yazar Katkıları:}

Konsept: Ş.T., M.R.G.

Literatür Tarama: Ş.T., M.R.G.

Tasarım: Ş.T.

Veri toplama: Ş.T.

Analiz ve yorum: Ş.T., M.R.G.

Makale yazımı: S.T., M.R.G.

Eleştirel incelenmesi: M.R.G.
Çıkar Çatışması: Herhangi bir çıkar çatışmamız bulunmamaktadır.

Finansal Destek: Araştırma kapsamında herhangi bir kurum ya da kuruluştan finansal destek sağlanmamıştır.

\section{Kaynaklar}

1. Şıklar E, Tunalı D. Çalışanların tükenmişlik düzeylerinin incelenmesi: Eskişehir örneği . Dumlupınar Üniversitesi Sosyal Bilimler Dergisi. 2012;33:75-84.

2. Freudenberger H J . Staff Burn-out. Journal of Social Issues. 1974;30(1):159-165.

3. Arı GS, Bal EÇ. Tükenmişlik Kavramı: Birey ve Örgütler Açısından Önemi .Yönetim ve Ekonomi Dergisi.2008;15(1):131-148.

4. Ince NB, Şahin AE. The Adaptation Study of Maslach Burnout Inventory-Educators Survey to Turkish. Journal of Measurement and Evalution in Education and Psychology . 2015;6(2):385-399

5. Maslach C, Jackson SE. "The Measurement of Experienced Burnout". Journal of Occupational Behavior. 1981;2:99113

6. Çimen M: "Türk Silahlı Kuvvetleri Sağlık Personelinin Tükenmişlik, İş doyumu, Kuruma Bağlılık ve Işsten Ayrılma Niyetlerine iliş̧kin Bir Alan Araştırması". Doktora Tezi, T. C. Genelkurmay Başkanlığı Gülhane Askeri Tıp Akademisi Sağlık Bilimleri Enstitüsü Sağlık Hizmetleri Yönetimi Bilim Dalı, 1981.

7. Cordes CL, Dougherty TW. "A Review and an Integration of Research on Job", Academy of Management Review. 1993;18(4):621-656

8. De Hert S. Burnout in Healthcare Workers: Prevalence, Impact and Preventative Strategies. Local Reg Anesth. 2020;13:171-183

9. www.wilmarschaufeli.nl [homepage on the Internet]. Netherlands: Burnout in Europe: relations with national economy, governance, and Organizational Psychology and Professional Learning [cited October 2018]. Available from: https://www.wilmarschaufeli.nl/publications/Schaufeli/500.pdf.

10. Rodrigues H, Cobucci R, Oliveira A, Cabral JV, Medeiros L, Gurgel $\mathrm{K}$, et al. Burnout syndrome among medical residents: A systematic review and meta-analysis. PLoS ONE . 2018;13(11):e0206840

11. Panagioti M, Geraghty K, Johnson J, Zhou A, Panagopoulou E, Chew-Graham C, et al. Association Between Physician Burnout and Patient Safety, Professionalism, and Patient Satisfaction: A Systematic Review and Meta-analysis. JAMA Intern Med. 2018;178(10):1317-1331.

12. Ergin C. Doktor ve hemşirelerde tükenmişlik ve Maslach tükenmişlik ölçeğinin uyarlanması. VII. Ulusal Psikoloji Kongresi Bilimsel Çalışmaları El Kitabı. Türk Psikologlar Derneği Yayını. 1992:143-54.

13. Tanrıverdi EÇ, Dikbaş L, Çalıkoğlu EO, Koca Ö, Kadıoğlu BG.The Relation Between The Levels of Burnout and Job Satisfaction of Health Personnel Working in a Maternity Hospital and Sociodemographic Factors. Bakırköy Tıp Dergisi.2017;13(1):32-39.

14. Önen SÖ, Kuman TÖ, Sertöz N, Hepdurgun C, İşman HD, Bor C. Burnout in Healthcare Professionals During the Covid-19 Pandemic in a Tertiary Care University Hospital: Evaluation of the Need for Psychological Support. Türk Psikiyatri Dergisi. 2021;32(2):75-86. 
15. Ahola K, Honkonen T, Isometsä E, Kalimo R, Nykyri E, Koskinen $S$, et al. Burnout in the general population. Results from the Finnish Health 2000 Study. Soc Psychiatry Psychiatr Epidemiol. 2006;41(1):11-7.

16. Al-Ma'mari NO, Naimi Al, Tulandi T. Prevalence and predictors of burnout among obstetrics and gynecology residents in Canada. Gynecol Surg. 2016; 13(4):323- 327.

17. Medscape.com [homepage on the Internet]. New York: National Physician Burnout \& Suicide Report [cited 15 October 2020]. Available from: https://www.medscape.com/slideshow/2020-lifestyle -burnout-6012460.

18. Houkes I, Winants Y. Development of Burnout over time and the causal order of the three dimensions of burnout among male and female GP's. A three wave panel study. BMC Public Health. 2011;11:240-253.

19. 19-Molina PJ, Ramirez BL, Gómez UJL, Cañadas GR, De la Fuente EI, Cañadas-De la FGA. Levels of Burnout and Risk Factors in Medical Area Nurses: A Meta-Analytic Study. Int J Environ Res Public Health. 2018;15(12):2800-2816.

20. Castelo-Branco C, Figueras F, Eixarch E, Quereda F, Cancelo MJ, González S, et al. Stress symptoms and burnout in obstetric and gynaecology residents. BJOG. 2007;114(1):94-8.

21. Suleiman-Martos N, Albendín-García L, Gómez-Urquiza JL, Vargas-Román K, Ramirez-Baena L, Ortega-Campos E, et al. Prevalence and Predictors of Burnout in Midwives: $A$ Systematic Review and Meta-Analysis. Int J Environ Res Public Health. 2020;17(2):641.

22. 22-Dinç K: Yardım mesleklerinde tükenmişlik sendromu. Yüksek Lisans Tezi, Ankara: Ankara Üniversitesi Sosyal Bilimler Enstitüsü, 2008.

23. 23- Oğlak SC, Obut $\mathrm{M}$. The risk of vicarious trauma among front-line and non-front-line midwives and nurses. Aegean J Obstet Gynecol. 2020;2(2):1-4.

24. 24- Shanafelt TD, Boone $S$, Tan L, Dyrbye LN, Sotile W, Satele $D$, et al. Burnout and satisfaction with work-life balance among US physicians relative to the general US population. Arch Intern Med. 2012;172(18):1377-85.

25. 25- De Hert S. Burnout among anesthesiologists: it's time for action. J Cardiothor Vasc Anesth. 2018;32:2467-2468. 